
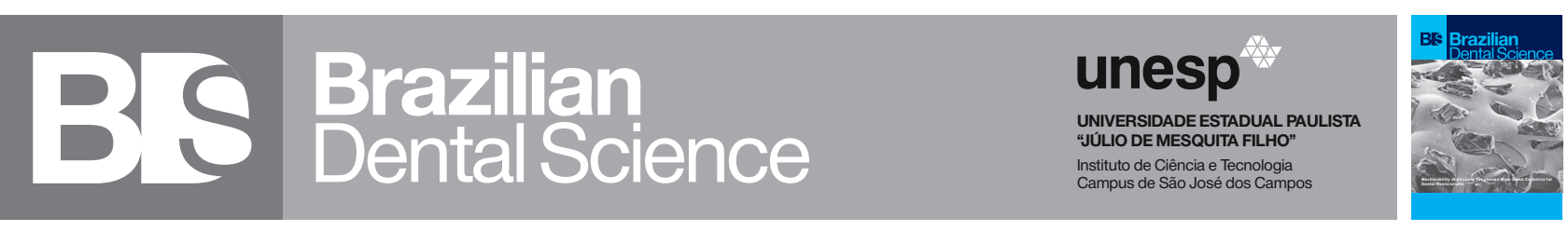

\title{
Do HIV patients have mandibular osteoporotic alterations? A mandibular cortical index case-control study
}

Pacientes com infecção por HIV tem alterações osteoporóticas na mandíbula? Um estudo caso controle utilizando o índice da cortical mandibular

Aline Yukari NAGAI ${ }^{1}$, Lucas MORITA ${ }^{1}$, Luciana MUNHOZ ${ }^{1}$, Emiko Saito ARITA ${ }^{1}$

1 - Department of Stomatology, School of Dentistry, São Paulo University, 2227 Lineu Prestes Avenue. Zip Code: 05508-000 São Paulo, SP, Brazil.

\section{ABSTRACT}

Objective: The objective of this study was to evaluate mandibular osteoporotic alterations in patients with HIV infection in comparison to non-HIV-infected patients using panoramic radiographs. Material and Methods: 26 HIV-infected patients and 142 non-HIV-infected patients (control group) were included in this study. Panoramic radiographs of the participants were assessed considering mandibular cortical index (MCI). Non-parametric comparisons between groups were performed, using Mann-Whitney test, at a level significance level of $p=0.05$. Results: HIV-infected patients presented lower bone mineral density (BMD) at mandible, assessed by MCI in panoramic radiographs when compared to non-HIV-infected patients. The medication intake of HIV-infected patients was highly heterogeneous and could not be associated to the low BMD presented in the mandibular cortex. Conclusions: HIV-infected patients may present lower mandibular BMD than non-HIV-infected patients.

\section{KEYWORDS}

Panoramic radiograph; osteoporosis; bone mineral density; HIV.

\section{RESUMO}

Objetivo: O objetivo deste estudo foi avaliar as alterações osteoporóticas mandibulares em pacientes com infecção por HIV comparandoos com pacientes não infectados, por meio de radiografias panorâmicas. Material e Métodos: 26 pacientes infectados pelo HIV e 142 pacientes não infectados (grupo controle) foram incluídos neste estudo. As radiografias panorâmicas dos participantes foram avaliadas considerando o índice da cortical mandibular (MCI). Comparações não paramétricas entre os grupos foram realizadas, com o teste de MannWhitney e nível de significância de $\mathrm{p}=0,05$. Resultados: Pacientes infectados pelo HIV apresentaram menor densidade mineral óssea (BMD) na mandíbula, avaliada pelo MCI em radiografias panorâmicas, quando comparados aos pacientes não infectados pelo HIV. A ingestão de medicamentos de pacientes infectados pelo HIV foi altamente heterogênea e não pôde ser associada à baixa BMD apresentada no córtex mandibular. Conclusões: Pacientes infectados pelo HIV podem apresentar BMD mandibular menor do que pacientes não infectados pelo HIV.

\section{PALAVRAS-CHAVE}

Radiografia panorâmica; Osteoporose; Densidade mineral óssea e HIV. 


\section{INTRODUCTION}

A pproximately 43 million people are infected by the human immunodeficiency virus (HIV), and the number of cases is increasing every year [1]. The treatment for suppression of HIV replication is effective in the progression of the disease, [2] although does not cure the HIV infection [1]. Hence, HIV patients can survive in asymptomatic chronic stages with reduced viral load [1].

Osteoporosis is a worldwide prevailing disease affecting nearby 27.5 million only in Europe, and more than 20 million Brazilians over 65 years old [3-5]. This disorder occurs when the process of bone remodeling becomes unbalanced due to major reabsorption of osteoclasts rather than osteoblasts $[6,7]$. There are several factors associated with this disorder such as lifestyle, menopause, endocrine hormones, cytokines and drugs that may affect bone remodeling $[6,7]$. Osteoporotic fractures is the most frequent clinical finding of osteoporosis, and these fractures may lead to morbidity and mortality [8]. As ageing, HIV patients can experience relatively higher reduction on bone mineral density (BMD) than general population [1]. Dual X-Ray Absorptiometry (DXA) is the method of choice to diagnose osteoporosis [9].

DXA scan is an accurate test to measure bone mineral density (BMD) and to diagnose osteoporosis [10]. Based on World Health Organization (WHO) criteria, the DXA result of a T-score of $\geq-1$ is considered normal; between - 1.0 and -2.5 is considered as osteopenia or low bone mass; and a T-score of $\leq$ -2.5 corresponds to a diagnosis of osteoporosis [11]. DXA examinations can also be used to monitor response to treatment, predict fracture risk and has the ability to verify effectiveness of antifracture therapies [12].

Although DXA scan is the most accepted method for BMD evaluation, it is an expensive examination [13] and has limited accessibility in developing countries [14]. Hence, imaging examinations such as panoramic radiographs, often requested by dental professionals, can be applied as an opportunistic screening tool for the identification of patients with high risks low BMD [13]. Panoramic radiographs have advantages as their low cost, wide easy access and a low radiation exposure [15].

Mandibular cortical index (MCI), obtained from panoramic radiographs, is a reliable radiomorphometric index in the screening patients with low BMD $[16,17]$. MCI reliability was exhausted confirmed by a broad range of researchers, which verified its correlation with BMD $[8,15,17,18]$. Briefly, the MCI is a qualitative assessment of the endosteal margin of mandible, specifically between the bicuspids and molar area, in which the presence of radiolucent defects is verified [17].

In HIV-infected patients, the pathogenesis of osteoporosis differs from the general population, as a number of modificatory factors, such as the intake of antiretrovirals, may alter the bone metabolism [19,20]. The decrease in BMD in HIV-infected patients treated with antiretrovirals is pronounced during the first six months after first exposure to antiretrovirals, but stabilize in long-term therapy [21]. However, it is hypothesized that the decrease of BMD in HIV patients may be related to hormonal changes caused by antiretrovirals that affects bone turnover [22]. Considering the types of antiretrovirals that are more often related to BMD decrease in HIV-infected patients, literature points that among nucleoside reverse transcriptase inhibitors, zidovudine can increase osteoclast activity and tenofovir can prejudice bone mineralization [23].

Hence, HIV-infected patients may present higher frequency of deleterious effects of osteoporosis at younger ages, due to the antiretroviral medication intake. As DXA is not frequently performed in younger patients, but, 
eventually, panoramic radiographs could be performed in the beginning of dental treatments, MCI can be applied as a screening tool to low BMD in these patients.

Thus, this investigation aimed to assess the mandibular BMD of HIV-infected patients, using the MCI from panoramic radiographs. Additionally, MCI from HIV-infected patients was compared with MCI of non-HIV-infected patients, with the same age and the same gender.

\section{MATERIAL AND METHODS}

Study participants and inclusion and exclusion criteria

This retrospective study was conducted with 26 patients who had a confirmed diagnosis of HIV infection (from the 23607.888 São Paulo, Brazil) and 142 non-HIV-infected patients (from São Paulo University Dentistry School, Brazil) who underwent panoramic radiographic examinations for dental treatment. Approval was obtained from the Ethics Committee at São Paulo University Dentistry and Medicine School, Dentistry University database.

The guidelines of Helsinki were followed in this investigation.

Panoramic radiographic examinations with technical failures were excluded. The nonHIV-infected patients (control group) were selected randomly in order to match the age and gender of the HIV-infected patients.

MCI analysis was performed independently by four experienced radiologists two weeks apart to avoid memory bias. Intraobserver reliability was assessed between measurements. The radiologists assessed the appearance of the cortical bone at the mandibular endosteal margin on both sides of the mandible, between the mental foramen to the posterior limit of the angle of the mandible, using the MCI (Klemmeti) classification proposed in 1994 [17]. This classification is as follows: $\mathrm{C} 1=$ normal, when a sharp and marked continuous endosteal margin is observed; C2 $=$ moderately eroded, with evidence of lacunar resorption and $\mathrm{C} 3=$ severely eroded. A schematic explanation of the aforementioned is available on Figure 1. A figure containing panoramic radiographs of this sample is demonstrated on Figure 2.

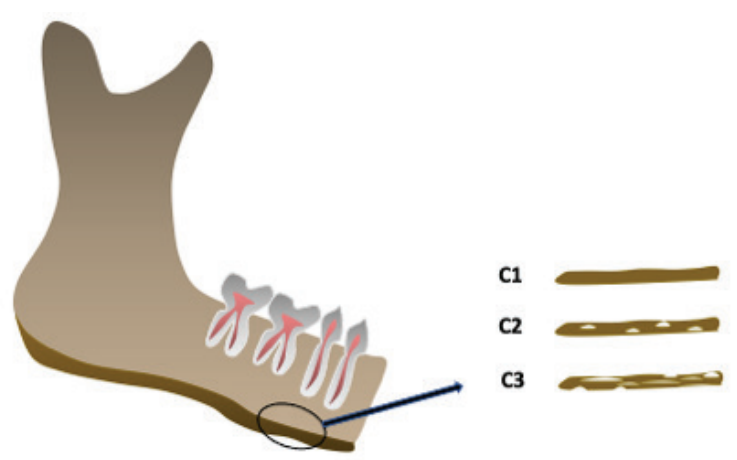

Figure 1 - Schematic representation of the endosteal margin classification.

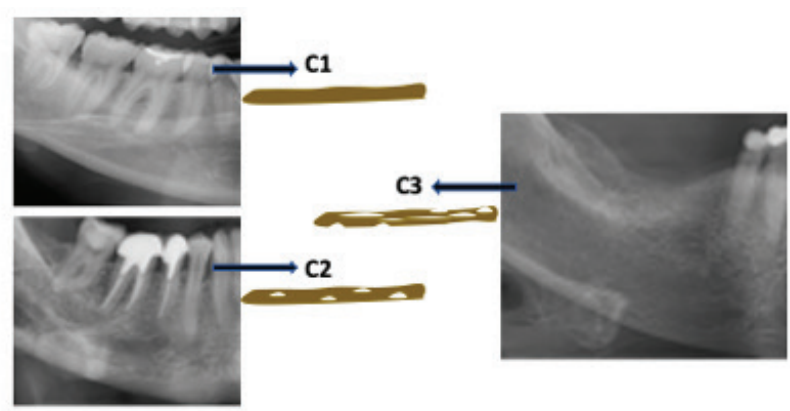

Figure 2 - Panoramic radiographs of the present study with their specific classifications.

\section{Statistical Analysis}

For MCI, non-parametric comparisons between groups (Mann-Whitney test.) were performed. Intra- and inter-observer agreement was assessed using the Kappa test. Agreement between observers for MCI was evaluated using this study panoramic radiographs in random order and with a seven-day interval between MCI assessments to avoid memory bias.

All statistical analyses were performed using the IBM SPSS Statistics 24 software (SPSS, Inc., Chicago, IL, USA). 


\section{RESULTS}

\section{Descriptive data}

Table I depicts the number, gender, median age of HIV-infected patients, as well as the medication intake description. A detail of the HIV-infected patients with MCI C2 and C3, which is associated with low BMD at mandible according to medication intake is also described.

Table I - Descriptive statistics of HIV-infected patients. Median age, gender, medication intake and a detail of C2 and C3 mandibular cortical index patient's medication intake

\begin{tabular}{|c|c|c|}
\hline Variable & & \\
\hline Total of patients assessed & 26 & \\
\hline Median age & $51(26-73)$ & \\
\hline Gender & Number of patients & $\begin{array}{l}\mathrm{C} 2 \text { and C3 patients } \\
\text { according to the medica- } \\
\text { tion intake }\end{array}$ \\
\hline Male & 5 & \\
\hline Female & 21 & \\
\hline \multicolumn{3}{|l|}{ Medication intake } \\
\hline$A Z T+3 T C+$ Biovir & 6 & 3 \\
\hline Biovir + Kaletra & 1 & 1 \\
\hline $\mathrm{TDF}+3 \mathrm{TC}+\mathrm{EFV}$ & 2 & 2 \\
\hline Biovir + ATZ + Ritonavir & 2 & 1 \\
\hline $\mathrm{TDF}+3 \mathrm{TC}+\mathrm{EFV}$ & 2 & 1 \\
\hline$A Z T+A T Z+3 T C+$ vit $A e D$ & 1 & 1 \\
\hline TDF + 3TC + RALT + Duran & 1 & 1 \\
\hline TNF + 3TC + EFV & 1 & 1 \\
\hline Biovir + EFV & 2 & 2 \\
\hline AZT + 3TC + Kaletra & 2 & 2 \\
\hline $\mathrm{AZT}+3 \mathrm{TC}+\mathrm{EFV}$ & 2 & 1 \\
\hline$A Z T+E T C+N V P$ & 1 & 1 \\
\hline NEV + EST + LAMI & 1 & \\
\hline Puran T4U Assert & 2 & \\
\hline
\end{tabular}

Regarding to MCI, differences between groups are available in Table II. The HIV-infected patients presented a higher MCI classification (median $=2$ ) than non-HIV-infected patients $($ median $=1)$, with a $\mathrm{p}$ value of 0.067 .
Table II - Mandibular cortical index classification for HIVinfected patients and non-HIV-infected patients (control group) and differences between groups according to Mann-Whitney test

\begin{tabular}{|c|c|c|}
\hline $\begin{array}{c}\text { Mandibular cortical } \\
\text { index }\end{array}$ & HIV & Control \\
\hline $\mathrm{C1}$ & 12 & 94 \\
\hline C2 & 12 & 39 \\
\hline C3 & 2 & 9 \\
\hline Median & $2 \mathrm{a}$ & $1 \mathrm{~b}$ \\
\hline Total & 26 & 142 \\
\hline pvalue & \multicolumn{2}{|c|}{$p=0.067$} \\
\hline
\end{tabular}

The Kappa test for MCI showed significant intra and interobserver values $(0.82(\mathrm{p}=0.01)$ and $0.87(\mathrm{p}=0.02)$, respectively).

\section{DISCUSSION}

In the present study, we found that HIVinfected patients presented lower mandibular BMD, when assessed using MCI in panoramic radiographs, when compared to non-HIVinfected patients. As MCI can be applied as a screening tool to low BMD and previous researchers considering HIV-infected patients mention the higher risk of osteoporosis in HIVinfected patients, our findings corroborate and emphasize the literature.

It is well known that the prevalence of low BMD in HIV-infected patients is relatively higher when compared to the general population [24]. HIV-infected patients are believed to be three times more likely to present osteoporosis than non-HIV-infected patients [23]. HIV infection and the use of antiretroviral drugs (ART) modifies the regulatory markers of bone absorption and resorption, leading to lower BMD [25].

Effective combined ART uses drugs targeting viral enzymes in HIV infections (26). Based on their resistance profiles and molecular mechanisms, these drugs are divided into six distinct classes: nucleoside/ nucleotide reverse transcriptase inhibitors (NRTIS), non-nucleoside 
reverse transcriptase inhibitors (NNRTIs), integrase inhibitors, protease inhibitors (PIs), fusion inhibitors and co-receptor antagonists [27].

Although certain sociodemographic characteristics of individuals with HIV infection, such as smoking and liver disease, may be prone to low BMD, it is established that exposure to antiretroviral therapy affects BMD directly and indirectly, with the impact on BMD differing between the ART classes and among the individual antiretroviral agents within a given class of drugs [19]. In the present study sample of HIV-infected patients, it was not possible to correlate a specific ART to the low BMD as the combination of drugs are highly heterogeneous.

Some studies show that the initiation of ART use reduces the BMD from $6 \%$ to $2 \%$ in 1 to 2 years [28]. Greater losses in BMD at the beginning of treatment with ART are observed with the use of nucleoside / nucleotide reverse transcriptase inhibitors and protease inhibitors, but less with the integrase inhibitor raltegravir [19].

The extent of BMD loss depends in part on the specific drugs used in the treatment [29]. Furthermore, the characteristics and magnitude of the change in BMD between HIV viremic and HIV avirenic infected patients may occur [19].

Moreover, the reduction in BMD in HIVinfected patients can occur as a secondary event to the immune reconstitution and / or an effect of ART on bone metabolism. BMD modifications may occur due to a pattern of early increases in bone resorption markers, followed by delayed increases in bone formation markers [30].

The most negative outcome of osteoporosis is the low-energy fractures due to low BMD $[6,31]$. Considering the aforementioned, Triant et al. found that fractures prevalence was higher in HIV-infected patients when compared to a control group [32].

Within the context of dentistry, Lemos et al. systematic review found that HIV-infected patients with dental implants, performed similarly to non-HIV-infected patients patients. As long as the risk factors and CD4+ cell count are controlled, dental implant is a viable treatment [33-35]. In addition, Medeiros et al. showed that osteoporotic patients also did not show a difference in the performance of the oral implants compared to non-osteoporotic patients [35]. So far it seems that a low BMD in HIVinfected patients does not affect dental implants performance, however, there are no studies that investigate the relationship of all these factors simultaneously.

When evaluating mandibular BMD modifications in HIV-infected patients, Caputo et al. observed that postmenopausal women presented higher risk of low BMD when compared to non-HIV infected patients, which is in concordance with the present study [36].

Patients with a moderately eroded endosteal margins, as detected in MCI, have a significant chance to have at least osteopenia. According to Calciolari et al., the presence of any cortical erosion in endosteal margin, verified by MCI, can be applied as a low BMD indicator, with a chance of $80 \%$ of these patients have at least osteopenia [37].

The limitations of the present investigation are the retrospective nature of this investigation, the limited number of patients and the lack of information regarding to the HIV status of the HIV-infected patients, such as the lack of information related to viremia and CD4 + cell count of HIV-infected patients.

\section{CONCLUSIONS}

Within the limitations of the present study, in conclusion, patients with HIV infection may present lower mandibular BMD, when compared to non-HIV-infected patients. Further larger samples studies should be performed in order to investigate mandibular BMD in HIVinfected patients and dentists should be aware 
of the possibility to screen these patients using panoramic radiographs, in order to avoid lowenergy fractures and provide proper refer to early treatment for systemic low BMD.

\section{Conflicts of interest}

Lucas Morita, Aline Nagai, Luciana Munhoz, and Emiko Saito Arita declares no conflicts of interest.

No financial support to report.

\section{REFERENCES}

1. Brody C, Sok S, Tuot S, Pantelic M, Restoy E, YiS. Do combination HIV prevention programmes result in increased empowerment, inclusion and agency to demand equal rights for marginalised populations in low-income and middle-income countries? A systematic review. BMJ Glob Health. 2019 Out:4(5):e001560. doi:10.1136/bmigh-2019-001560

2. Rodger AJ, Lodwick R, Schechter M, Deeks S, Amin J, Gilson R, etal. Mortality in well controlled $\mathrm{HIV}$ in the continuous antiretroviral therapy arms of the SMART and ESPRIT trials compared with the general population. AIDS. 2013 Mar;27(6):973-9.doi:10.1097/QAD.0b013e32835cae9c

3. Hernlund E, Svedbom A, lvergård M, Compston J, Cooper C, Stenmark J, et al. Osteoporosis in the European Union: medical management, epidemiology and economic burden. A report prepared in collaboration with the International Osteoporosis Foundation (IOF) and the European Federation of Pharmaceutical Industry Associations (EFPIA). Arch Osteoporos. 2013 Oct;:8:136. doi:10.1007/s11657-013-0136-1.

4. Marinho BC, Guerra LP,Drummond JB, Silva BC, Soares MM. The burden of osteoporosis in Brazil. Arq Bras Endocrinol Metabol. 2014 Jul;:58(5):434-43. doi:10.1590/0004-2730000003203

5. Baccaro LF, Conde DM, Costa-Paiva L, Pinto-Neto AM. The epidemiology and management of postmenopausal osteoporosis: a viewpoint from Brazil. Clin Interv Aging.2015 Mar;10:583-91.doi: 10.2147/CIA.S54614

6. BillingtonEO, Reid IR. Pathogenesis of Osteoporosis. In: Huhtaniemi I,Martini L, editors. Encyclopedia of Endocrine Diseases (Second Edition). Oxford: Academic Press; 2019. p. 222-32

7. Yedavally-Yellayi S, Ho AM, Patalinghug EM. Update on Osteoporosis. Primary Care: Clinics in Office Practice. 2019 Mar;46(1):175-90. doi:10.1016/j. pop.2018.10.014

8. Munhoz LCl, Miura DK, Watanabe PCA, Arita ES. Bone mineral density and mandibular osteoporotic alterations in panoramic radiographs: Correlation by peripheral bone densitometry in men. Indian J Den Res. 2019;31(3):457-64. doi: 10.4103/ijdr.JJDR 44018

9. Assessment of fracture risk and its application to screening for postmenopausal osteoporosis. Report of a WHO Study Group. World Health Organ Tech Rep Ser. 1994;843:1-129.

10. Nayak S, Edwards DL, Saleh AA, Greenspan SL.Systematic review and meta-analysis of the performance of clinical risk assessment instruments for screening for osteoporosis or low bone density. Osteoporos Int. 2015 Feb;26(5):1543-54.doi: 10.1007/s00198-015-3025-1
11. Garg MK, Kharb S. Dual energy X-ray absorptiometry: Pitfalls in measurement and interpretation of bone mineral density. Indian J Endocrinol Metab. 2013 Mar;:17(2):203-10.doi: 10.4103/2230-8210.109659

12. Blake GM, Fogelman I. The role of DXA bone density scans in the diagnosis and treatment of osteoporosis. Postgrad Med J.2007 Mar;83(982):509-17.doi: 10.1136/pgmj.2007.057505

13. Kim OS, Shin MH, Song IH, Lim IG, Yoon SJ, Kim OJ, etal. Digital panoramic radiographs are useful for diagnosis of osteoporosis in Korean postmenopausal women. Gerodontology.2016 Jun;33(2):185-92.doi:10.1111/ ger.12134

14. Wan CS, Ward LC, Halim J, Gow ML, Ho M, Briody JN, etal. Bioelectrical impedance analysis to estimate body composition, and change in adiposity, in overweight and obese adolescents: comparison with dual-energy x-ray absorptiometry. BMC Pediatr.2014 0ct;14:249. doi: 10.1186/1471-2431-14-249.

15. Choil,MunhozL, Arita ES. Assessment of Osteoporotic Alterations in Brazilian Postmenopausal Women: A Retrospective Study. Journal of Clinical and Dental Research. 2018 May;12(5):ZC34-ZC7. doi:10.7860/JCDR/2018/34529.11566

16. Munhoz L, Aoki EM, Cortes ARG, de Freitas CF,AritaES. Osteoporotic alterations in a group of different ethnicity Brazilian postmenopausal women: An observational study. Gerodontology.2018;35(2):101-109. doi: 10.1111/ ger.12322.

17. KlemettiE, Kolmakov S, Kröger H. Pantomography in assessment of the osteoporosis risk group. Scand J Dent Res. 1994 Jun;102(1):68-72 doi: 10.1111/.1.1600-0722.1994.tb01156.x.

18. Pallagatti S, Parnami P,Sheikh S, Gupta D. Efficacy of Panoramic Radiography in the Detection of Osteoporosis in Post-Menopausal Women When Compared to Dual Energy X-Ray Absorptiometry. Open Dent J. 2017 Jun;11:350-9. doi: $10.2174 / 1874210601711010350$

19. Mallon PWG. Aging with HIV: osteoporosis and fractures. Current opinion in HIV and AIDS. 2014 Jul;9(4):428-35. doi:10.1097/COH.0000000000000080

20. Mallon PWG. HIV and bone mineral density. Current Opinion in Infectious Diseases. 2010 Feb;23(1):1-8.doi:10.1097/QC0.0b013e328334fe9a.

21. Zhang L, Su Y,HsiehE, Xia W, Xie J, Han Y, etal. Bone turnover and bone mineral density in HIV-1infected Chinese taking highly active antiretroviral therapy -a prospective observational study. BMC MusculoskeletDisord. 2013 Jul;14:224. doi: 10.1186/1471-2474-14-224

22. Unsal AB, Mattingly AS, Jones SE, Purdy JB, Reynolds JC, Kopp JB, etal. Effect of Antiretroviral Therapy on Bone and Renal Health in Young Adults Infected With HIV in Early Life. J Clin Endocrinol Metab. 2017 Aug;102(8):2896-904. do: 10.1210/jc.2017-00197.

23. Brown $T T$, Qaqish RB. Antiretroviral therapy and the prevalence of osteopenia and osteoporosis: a meta-analytic review. Aids Mar.2006;20(17):2165-74. doi:10.1097/QAD.0b013e32801022eb.

24. Mallon PW. HIV and bone mineral density. Curr Opin InfectDis. 2010 Feb;23(1):18.doi:10.1097/QCO.0b013e328334fe9a.

25. Slama L, Reddy S, Phair J, PalellaFJ, Jr, Brown TT. Changes in bone turnover markers with HIV seroconversion and ART initiation. J Antimicrob Chemother. 2017 0ct;72(5):1456-61.doi:0.1093/jac/dkx011.

26. Bandera A, Gori A, Clerici M, Sironi M. Phylogenies in ART: HIV reservoirs, HIV latency and drug resistance. Curr Opin Pharmacol. 2019 Out;48:24-32. doi: 10.1016/j.coph.2019.03.003

27. Arts EJ, Hazuda DJ. HIV-1antiretroviral drug therapy. Cold Spring Harb Perspect Med. 2012 Apr;2(4):a007161. doi:10.1101/cshperspecta007161. 
28. McComsey GA, KitchD, Daar ES, Tierney C, Jahed NC, Tebas P, etal. Bone mineral density and fractures in antiretroviral-naive persons randomized to receive abacavir-lamivudine or tenofovir disoproxil fumarate-emtricitabine along with efavirenz or atazanavir-ritonavir: Aids Clinical Trials Group A5224s, a substudy of ACTG A5202. JInfect Dis. 2011 Jun;203(12):1791-801. doi:10.1093/ infdis/jir188.

29. Brown TT,Moser C, Currier JS, Ribaudo HJ, Rothenberg J, Kelesidis T, etal. Changes in Bone Mineral Density After Initiation of Antiretroviral Treatment With Tenofovir Disoproxil Fumarate/Emtricitabine Plus Atazanavir/Ritonavir, Darunavir/Ritonavir, or Raltegravir. J Infect Dis. 2015 0ut;212(8)::1241-9. doi: 10.1093/infdis/jiv194

30. Cotter AG, Vrouenraets SM, Brady JJ, WitFW, Fux CA, Furrer H, etal. Impact of switching from zidovudine to tenofovir disoproxil fumarate on bone mineral density and markers of bone metabolism in virologically suppressed HIV-1 infected patients; a substudy of the PREPARE study. J Clin Endocrinol Metab. 2013 Apr;98(4):1659-66. doi:10.1210/jc.2012-3686

31. Armas LAG, Recker RR. Pathophysiology of Osteoporosis: New Mechanistic Insights. Endocrinology and Metabolism Clinics of North America. 2012 Sep;41(3):475-86.doi:10.1016/..ecl.2012.04.006
32 Triant VA, Brown TT, Lee H, Grinspoon SK. Fracture prevalence among human immunodeficiency virus (HIV)-infected versus non-HIV-infected patients in a large U.S. healthcare system. JClin Endocrinol Metab. 2008 Sep;93(9):3499504.doi: 10.1210/jc.2008-0828

33. Lemos CAA, Verri FR, Cruz RS, Santiago Junior JF, Faverani LP, Pellizzer EP. Survival of dental implants placed in HIV-positive patients: a systematic review. Int J Oral Maxillofac Surg. 2018 0ct;47(10):1336-42.doi:10.1016/j. ijom.2018.02.010

34. Rubinstein NC, JacobsonZ, McCausland GL, Dibart S. Retrospective study of the success of dental implants placed in HIV-positive patients. Int J Implant Dent. 2019 Jun;5(1):30. doi: 10.1186/s40729-019-0174-6

35. de MedeirosF,Kudo GAH, Leme BG, Saraiva PP, Verri FR, Honorio HM, etal. Dental implants in patients with osteoporosis: a systematic review with meta-analysis. Int J Oral Maxillofac Surg. 2018 Apr;47(4):480-91. doi:10.1016/j. ijom.2017.05.021.

36. Caputo BV, Traversa-Caputo GC, Costa C, Giovani EM. Evaluation of bone alterations in the jaws of HIV-infected menopausal women. Brazilian Ora Research. 2013 Apr;27:231-7.doi: 101590/S1806-83242013005000014

37. CalciolariE, Donos N, Park JC, Petrie A, Mardas N. Panoramic measures for oral bone mass in detecting osteoporosis: a systematic review and meta-analysis. JDentRes. 2015 Nov;94(3 Suppl):17s-27s. doi:10.1177/0022034514554949

\section{Luciana Munhoz}

\section{(Corresponding address)}

Department of Stomatology, School of Dentistry, University of São Paulo, 2227 Lineu

Prestes Avenue. Zip Code: 05508-000 São Paulo, SP, Brazil.

Date submitted: $2020 \mathrm{Apr} 17$

E-mail: dra.lucimunhoz@usp.br 